\title{
Editorial
}

International Archives of
Allergy
Immunology

Published online: November 21, 2012

DOI: $\underline{10.1159 / 000345363}$

\section{The Right Timing for Shrimp Tropomyosins}

\author{
L. Karla Arruda
}

Department of Medicine, School of Medicine of Ribeirao Preto, University of Sao Paulo, Sao Paulo, Brazil

It is well known that the timing of egg hatching for many marine organisms is key to species survival because the time span in which larvae are able to survive in the deep ocean is very short. If egg hatching is too early, they starve before the spring phytoplankton blooms, missing their food source. If hatching is delayed, they also miss the bloom. In most of the North Atlantic, shrimp eggs hatch just a few days before the spring bloom. Peter Koeller et al. [1] showed that the North Atlantic shrimp species Pandalus borealis has adapted its reproductive cycle very well to match hatching times with local temperatures and seasonal phytoplankton dynamics in different ecological regimes throughout its wide latitudinal range $\left(42-80^{\circ} \mathrm{N}\right)$. Although this strategy is susceptible to interannual oceanographic variability and long-term climatic changes, it has not prevented $P$. borealis from being the most commercially important coldwater shrimp species [2]. In allergy diagnosis, $P$. borealis extract is a component of in vitro and in vivo diagnostic testing reagents.

The increased consumption of seafood worldwide, due to its high nutritive value and the promotion of a healthy diet, has been accompanied by more frequent reports of adverse reactions among consumers and also among processors of seafood. Seafood includes fish, Crustacea (shrimp, crab, and lobster), and mollusks (squid, oysters, scallop, clams, and snails), with the latest two phyla gen-

\section{KARGER}

Fax +4161306 1234

E-Mail karger@karger.ch

www.karger.com
(C) 2012 S. Karger AG, Basel

$1018-2438 / 13 / 1604-0331 \$ 38.00 / 0$

Accessible online at:

www.karger.com/iaa erally referred to as shellfish. Shellfish allergy, including severe acute hypersensitivity reactions and life-threatening or even fatal anaphylaxis, has been considered one of the major contributors to food allergy [3]. Sicherer et al. [4] conducted a nationwide, cross-sectional, random telephone survey which censed 14,948 individuals, to estimate the prevalence of seafood allergy in the USA. The study revealed that shellfish allergy was encountered in $2.2 \%$ of the population, corresponding to more than 6 million Americans with this condition, and that it was almost 5 times more common among adults as compared to children. It has been appreciated that allergies to both fish and shellfish are usually not outgrown [5]. Interestingly, Ayuso et al. [6] showed that children with shrimp allergy recognized more shrimp proteins and individual peptides than adults, and that the intensity of IgE binding was also greater in children compared to adult patients, suggesting that clinical reactivity might decrease over time.

The muscle protein tropomyosin is considered to be responsible for most of the allergenic activity of shrimp $[3,7]$. Tropomyosin is also an important allergen in mollusks, as well as in other invertebrates including dust mites, cockroach, and parasites (Ascaris lumbricoides, Anisakis simplex, filarial species, and others), raising important issues about clinical implications of IgE cross- 
reactivity [8]. More recently, other allergens have been identified in crustaceans including arginine kinase (AK) [9], myosin light chain (MLC) [10], and a sarcoplasmic calcium-binding protein (SCP) [11]. The latter two may be of particular importance in children $[10,11]$.

Diagnosis of shrimp allergy relies on clinical history, skin prick testing, and in vitro testing for specific IgE; however, the sensitivity and specificity of these methods in relation to double blind, placebo-controlled food challenges, considered as the gold-standard diagnostic procedure, are not optimal. Recent studies have highlighted the value of measuring IgE to shrimp tropomyosin as an added tool for a more accurate diagnosis of shrimp allergy. Yang et al. [12] studied the relevance of sensitization to tropomyosin in dust mite-sensitized subjects also sensitized to shrimp. Tropomyosin-specific IgE was found to have greater diagnostic efficiency compared with whole shrimp-specific IgE or skin prick testing $(88.5,74.2$, and $65.7 \%$, respectively) to predict a positive oral challenge [12]. In keeping with these results among Brazilian patients, Gámez et al. [13] also demonstrated that measurements of IgE levels to shrimp tropomyosin (rPen a 1) provide added diagnostic value to skin prick testing or specific IgE to shrimp for confirmation of shrimp allergy in patients with suspected reactions in a European population [13].

In a recent issue of International Archives of Allergy and Immunology, Myrset et al. [14] reported the identification, cloning, and recombinant expression of tropomyosin from the Northern shrimp P. borealis ( $\mathrm{rPan} \mathrm{b} 1$ ). They showed that the sequence of $P$. borealis tropomyosin was $96.7-100 \%$ identical to those previously reported from other species of shrimp. In addition, they elegantly demonstrated that the recombinant protein presented a similar structure and comparable IgE binding pattern to the natural tropomyosin from $P$. borealis. One of the main issues is whether cloning and expression of tropomyosins from different shrimp species which might be relevant for particular areas of the world is really necessary for diagnosis and treatment purposes, considering the high degree of sequence identity among shrimp tropomyosins. The answer is probably yes; we should have a panel of not only shrimp tropomyosins but also other shrimp allergens identified to date, to increase our diagnostic accuracy of shrimp allergy and to develop novel therapeutic strategies for shrimp allergic patients.

A recent study by Ayuso et al. [15] investigated IgE responses to overlapping peptides of the Litopenaeus vannamei shrimp allergens Lit $\mathrm{v} 1$ (tropomyosin), Lit v 2
(AK), Lit v 3 (MLC), and Lit v 4 (SCP), by microarray technology, in comparison to IgE responses to shrimp natural allergens by immunoblotting. The results revealed that patients with positive shrimp challenges presented more intense and diverse epitope recognition to all four shrimp allergens. Diagnostic efficiency was higher for individual epitopes than for proteins. In particular, efficiency was highest for certain Lit v 1 and Lit v 2 epitopes, followed by Lit $\mathrm{v} 3$ and Lit $\mathrm{v} 4$ epitopes. The results strongly suggest that IgE antibodies to these shrimp epitopes could be used as biomarkers for predicting clinical reactivity in subjects with sensitization to shrimp. However, the findings reported in the study need to be validated by analysis of larger groups of sera of subjects with a clinically well-characterized status of sensitization versus clinical reactivity, possibly including patients from different ethnicities, before such tests can be considered for use in clinical practice [15].

Despite the high prevalence of shrimp allergy, the potential severity of the reactions, and the usual life-long persistence of this condition, there is still no treatment available. Many patients who present with shrimp allergy express the desire to eat shrimp and shellfish for their pleasant taste and/or nutritional value; others manifest their fear of accidental ingestion and development of a severe reaction. In these situations, it would be very helpful to offer therapeutic alternatives to food avoidance. The study by Myrset et al. [14] strengthens the potential use of tropomyosin in diagnostic tests to improve confirmation of shrimp allergy in patients with suggestive symptoms without the need for DBPCFC and, more importantly, it provides an important additional tool for the development of innovative therapeutic options for shrimp allergy such as specific immunotherapy. Other recombinant shrimp allergens in combination with tropomyosin could be used for similar purposes.

References dranath S, Richards A, Ouellet P: Orr D, Skúladóttir U, Wieland K, Savard L, Aschan $\mathrm{M}$ : Basin-scale coherence in phenology of shrimps and phytoplankton in the North Atlantic Ocean. Science 2009;324:791-793.

$\checkmark 2$ Pascoal A, Ortea I, Gallardo JM, Cañas B, Barros-Velázquez J, Calo-Mata P: Species identification of the Northern shrimp (Pandalus borealis) by polymerase chain reaction - restriction fragment length polymorphism and proteomic analysis. Anal Biochem 2012;421:56-67.

-3 Lopata AL, O'Hehir RE, Lehrer SB: Shellfish allergy. Clin Exp Allergy 2012;40:850-858. 
-4 Sicherer SH, Muñoz-Furlong A, Sampson HA: Prevalence of seafood allergy in the United States determined by a random telephone survey. J Allergy Clin Immunol 2004; 114:159-65.

-5 Tsabouri S, Triga M, Makris M, Kalogeromitros D, Church MK, Priftis KN: Fish and shellfish allergy in children: review of a persistent food allergy. Pediatr Allergy Immunol 2012;23:608-615.

6 Ayuso R, Sánchez-Garcia S, Lin J, Fu Z, Ibáñez MD, Carrillo T, Blanco C, Goldis M, Bardina L, Sastre J, Sampson HA: Greater epitope recognition of shrimp allergens by children than by adults suggests that shrimp sensitization decreases with age. J Allergy Clin Immunol 2010;125:1286-1293.

-7 Reese G, Schicktanz S, Lauer I, Randow S, Lüttkopf D, Vogel L, Lehrer SB, Vieths S: Structural, immunological and functional properties of natural recombinant Pen a 1 , the major allergen of Brown Shrimp, Penaeus aztecus. Clin Exp Allergy 2006;36:517524
$>8$ Santos AB, Rocha GM, Oliver C, Ferriani VP, Lima RC, Palma MS, Sales VS, Aalberse RC, Chapman MD, Arruda LK: Cross-reactive IgE antibody responses to tropomyosins from Ascaris lumbricoides and cockroach. J Allergy Clin Immunol 2008;121: 1040-1046.

9 Yu CJ, Lin YF, Chiang BL, Chow LP: Proteomics and immunological analysis of a novel shrimp allergen, Pen m 2. J Immunology 2003;170:445-453.

10 Ayuso R, Grishina G, Bardina L, Carrillo T, Blanco C, Ibáñez MD, Sampson HA, Beyer $\mathrm{K}$ : Myosin light chain is a novel shrimp allergen, Lit v 3. J Allergy Clin Immunol 2008; 122:795-802.

11 Ayuso R, Grishina G, Ibáñez MD, Blanco C, Carrillo T, Bencharitiwong R, Sánchez S, Nowak-Wegrzyn A, Sampson HA: Sarcoplasmic calcium-binding protein is an EFhand-type protein identified as a new shrimp allergen. J Allergy Clin Immunol 2009;124: 114-120.
12 Yang AC, Arruda LK, Santos AB, Barbosa MC, Chapman MD, Galvão CE, Kalil J, Morato-Castro FF: Measurement of IgE antibodies to shrimp tropomyosin is superior to skin prick testing with commercial extract and measurement of IgE to shrimp for predicting clinically relevant allergic reactions after shrimp ingestion. J Allergy Clin Immunol 2010;125:872-878.

13 Gámez C, Sánchez-García S, Ibáñez MD, López R, Aguado E, López E, Sastre B, Sastre J, del Pozo V: Tropomyosin IgE-positive results are a good predictor of shrimp allergy. Allergy 2011;66:1375-1383.

14 Myrset HR, Barletta B, Di Felice G, Egaas E, Dooper MMBW: Structural and immunological characterization of recombinant Pan b 1, a major allergen of Northern Shrimp, Pandalus borealis. Int Arch Allergy Immunol 2012;160:221-232.

15 Ayuso R, Sánchez-Garcia S, Pascal M, Lin J, Grishina G, Fu Z, Ibáñez MD, Sastre J, Sampson HA: Is epitope recognition of shrimp allergens useful to predict clinical reactivity? Clin Exp Allergy 2012;42:293-304. 